\title{
Energetic and spatial characterization of seismicity in the Algeria-Morocco region
}

\author{
M. Hamdache ${ }^{1, *}$, J.A. Peláez ${ }^{2}$, A. Kijko ${ }^{3}$, and A. Smit ${ }^{3}$ \\ ${ }^{1}$ Département Etudes et Surveillance Sismique, CRAAG, BP 63 Bouzareah, 16340-Algiers, Algeria. \\ ${ }^{2}$ Department of Physics, University of Jaén, Spain \\ ${ }^{3}$ University of Pretoria Natural Hazard Centre, Pretoria, South Africa \\ *Corresponding author \\ Tel/Fax: +213 (0) $231890 /+213$ (0) 23189101 \\ E-mail address: m_hamdache@hotmail.com (M. Hamdache)
}

\begin{abstract}
We estimate the energetic and spatial characteristics of seismicity in the AlgeriaMorocco region using a variety of seismic and statistical parameters, as a first step in a detailed investigation of regional seismic hazard. We divide the region into five seismotectonic regions, comprising the most important tectonic domains in the studied area: the Moroccan Meseta, the Rif, the Tell, the High Plateau, and the Atlas. Characteristic seismic hazard parameters, including the Gutenberg-Richter $b$-value, mean seismic activity rate, and maximum possible earthquake magnitude, were computed using an extension of the Aki-Utsu procedure for incomplete earthquake catalogues for each domain, based on recent earthquake catalogues compiled for northern Morocco and northern Algeria. Gutenberg-Richter $b$-values for each zone were initially estimated using the approach of Weichert (1980): the estimated $b$ values are $1.04 \pm 0.04,0.93 \pm 0.10,0.72 \pm 0.03,0.87 \pm 0.02$ and $0.77 \pm 0.02$ for the Atlas, Meseta, High Plateau, Rif and Tell seismogenic zones, respectively. The fractal dimension $D_{2}$ was also estimated for each zone. From the ratio $D_{2} / b$, it appears that the Tell and Rif zones, with ratios of 2.09 and 2.12, respectively, have the highest potential earthquake hazard in the region. The Gutenberg-Richter relationship analysis allows us to derive that in the Tell and Rif, the number of earthquake with magnitude above $M w 4.0$, since 1925 normalized to decade and to square cell with $100 \mathrm{~km}$ sides is equal to 2.6 and 1.91 , respectively. This study provides the first detailed information about the potential seismicity of these large domains, including maximum regional magnitudes, characteristics of spatial clustering, and distribution of seismic energy release.
\end{abstract}

Keywords Maximum magnitude, seismic hazard parameters, fractal dimension, AlgeriaMorocco region 


\section{Introduction}

Recent seismic activity in the Algeria-Morocco region (Figure 1) has included several damaging earthquakes. In particular, the El Asnam region (now Cheliff) suffered two of the most destructive and damaging earthquakes in northern Algeria on 9 September $1954(M w$ 6.8) and 10 October $1980\left(M_{s}\right.$ 7.3). The most significant recent event was the $M w 6.9$ Zemmouri earthquake of 21 May 2003, with an epicenter $\sim 50 \mathrm{~km}$ northeast of Algiers (Hamdache et al. 2004). In addition, northern Morocco experienced two damaging earthquakes near Al Hoceima on 26 May 1994 (Mw 6.0) and 24 February 2004 (Mw 6.3). The most recent destructive event in Morocco was the $M w 5.7$ Agadir earthquake of 29 February 1960, which caused extensive damage and about 12,000 deaths. The high number of casualties is attributed primarily to the widespread use of structural masonry in this region (Cherkaoui et al. 2012).

Seismic hazard values, estimated from earthquake magnitudes by analyzing the energetic seismicity and its spatial distribution characteristics, provide to engineers, architects, and development planners with critical information about the catastrophic potential of earthquake-prone areas. Therefore, the interest in the Seismology and seismotectonics of Algeria and Morocco is steadily increasing, both within the scientific community and among the general population, particularly regarding the mitigation of destructive events and seismic risk assessment of urban areas

The aim of this study is to estimate the spatial seismicity characteristics in the AlgeriaMorocco region by analyzing the maximum possible earthquake magnitude and the spatial clustering characteristics of the seismicity.

We begin by delineating and characterizing five key tectonic domains in the study area, based on the best available seismic and geological data. Various analyses are performed to derive the characteristic parameters of each domain.

In the first step, using the procedure of Weichert (1980), the parameters $a$ and $b$ of the Gutenberg-Richter law (Gutenberg and Richter 1954) are derived for each delineated zone. Each zone in the proposed model is characterized by the mean rate of $M w>4.0$ earthquakes normalized to 10 year intervals and square cells with $100 \mathrm{~km}$ sides. The spatial distribution of the seismicity in each defined zone is analyzed using the fractal dimension (Grassberger and Procaccia 1983). The Gutenberg-Richter relationship and fractal dimension $D_{2}$ are two common ways to interpret local seismotectonic activity; the ratio $D_{2} / b$ is used as an indicator 
of earthquake hazard potential for a given source zone (Bayrak and Bayrak 2012; Öztürk, 2012; Pailople and Choowang, 2014). Both the $b$-value and the fractal dimension $D_{2}$ are controlled by the tectonic stress levels of each source region (Scholz 1968; Öncel et al. 1996).

In the second part of our study, different seismic hazard parameters are estimated using the approach by Kijko and Smit (2012). This procedure utilizes all available information about regional seismicity, combining macroseismic information from the historical part of the catalog with instrumented periods of variable catalog completeness magnitudes. The $b$-values, maximum magnitude estimates, and return periods for different magnitudes are computed for each of the five source zones.

\section{Tectonic overview}

The Algeria-Morocco region (Figure 1), located at the margin of the African Plate, has been the subject of several studies in the last decade. Presently, the convergence of the African and Eurasian Plates has an approximate NNW-SSE direction, with relative velocity values on the order of 4-6 mm/year (Buforn et al. 2004; Nocquet and Calais 2004; Meghraoui and Pondrelli 2012). Various tectonic syntheses have been proposed at local to regional scales, taking into account a complex morphology characterized by deep basins and arcuate fault-and-thrust belts (Frizon de Lamotte et al. 2000; Negredo et al. 2002; Serpelloni et al. 2007; Beghoul et al. 2009; Meghraoui and Pondrelli 2012). Following Frizon de Lamotte et al. (2000), the region at the north-western edge of the African Plate (called the Nubian Plate) is subdivided into the main structural domains shown in Figure 1. The Sahara domain, characterized by a lack of significant Mesozoic-Cenozoic deformation, forms part of the Precambrian areas of Africa; it is clearly cratonized and generally not affected by major later deformations. Thus, in the area of this study, the Sahara can be treated as tectonically stable.

As described by Peláez et al. (2016), the Saharan domain is in contact with the Atlas Mountains, an intracontinental chain of Alpine age that forms the second tectonic domain in the study area. The Moroccan Meseta domain is situated to the north of the Atlas Mountains; to the west is the High Plateau domain of Algeria, which is in contact with the Rif and Tell mountains to the north. The Anti-Atlas Mountains of Morocco delineate a tectonic transition from the Saharan Shield to the Atlas mountain range. To the west, in Morocco, the High Atlas mountain range reaches the coast in the Agadir area, and continues to the northeast and east in two branches: the first trends E-W to central Tunisia, while the second extends north to form 
the Middle Atlas mountains, whose NE-SW direction separates the Moroccan Meseta from the High Plateau.

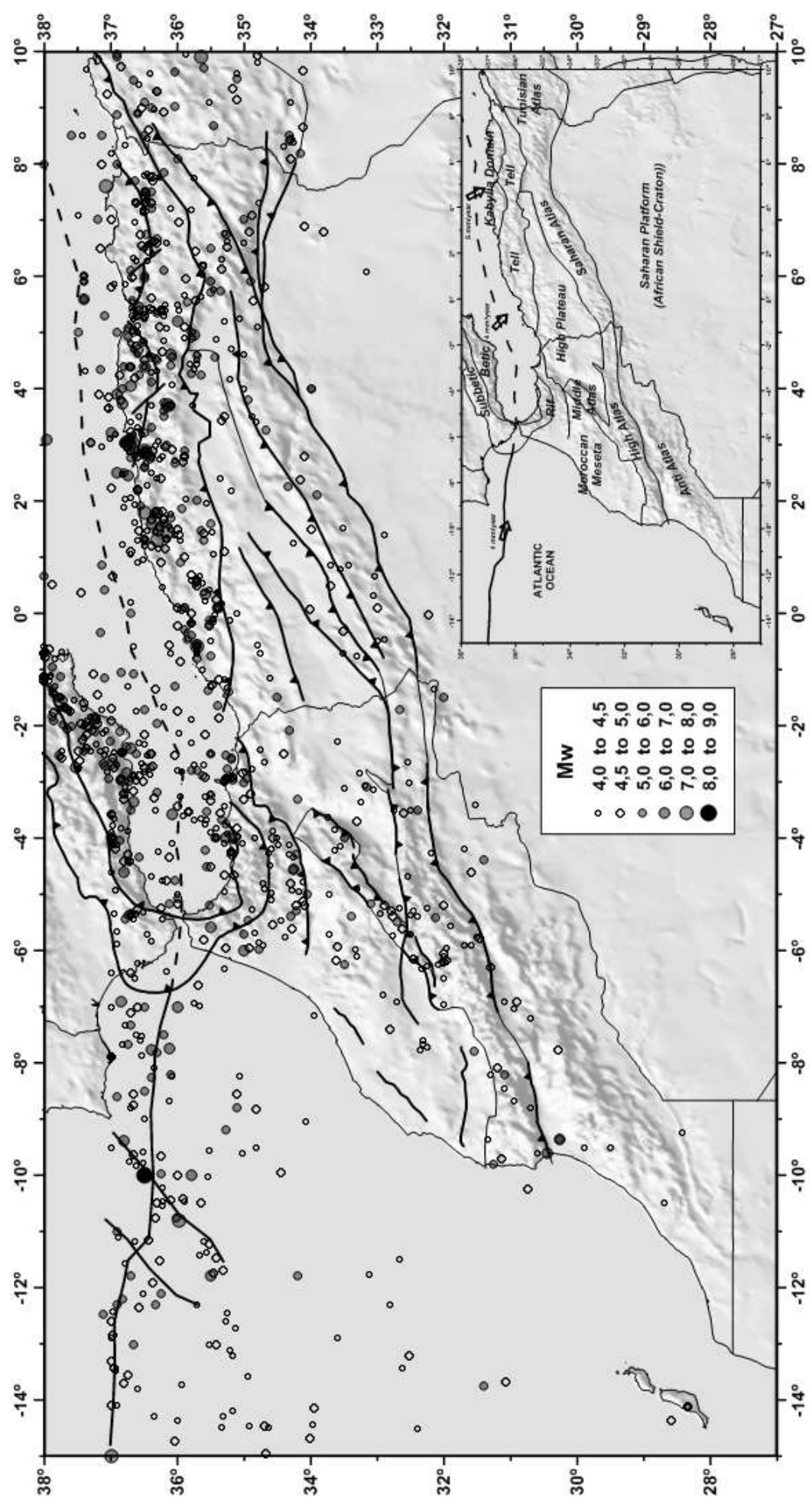

Figure 1: Map showing the main tectonic domains in the Algeria-Morocco region. The map diplays the seismicity and the velocity rate at the plate boundary between Eurasia and Africa Plates. 
The Tell-Rif system, as described by Frizon de Lamotte et al. (2000), comprises mountains formed by sedimentary external zones (only weakly affected by metamorphism) that were thrust southward toward the Moroccan Meseta, the High Plateau, and the Internal Zones (Negredo et al. 2002). The Internal Zones, located in the southern Betic Cordillera, are composed of mountain ranges separated by intermountain basins. They can be subdivided into the Betic and Rif-Tell orogenic systems, an east-west elongate arcuate Alpine orogenic belt. To the south of the Alboran Sea, in the North African Rif and Tell belts, the Internal Zones contain metamorphic rocks very similar to those of the Betic Cordillera (Lonergan and White 1997; López Casado et al. 2001). Broadly, the Internal Zones are fragments of a collisional mountain belt composed of Mesozoic sediments that were shortened during Cretaceous and Paleogene convergence (Calvert et al. 2000). Its Alpine chains formed from the Cretaceous to the Oligocene-Early Miocene. Later, numerous Neogene basins were formed, in many instances clearly cutting previous structures. From the late Miocene to the present, nearly NS-aligned compression created strike-slip faults (NE-SW sinistral and NW-SE dextral) and reverse faults, with many of the latter trending $\mathrm{N} 70^{\circ} \mathrm{E}$ to $\mathrm{N} 90^{\circ} \mathrm{E}$. In many instances, the strikeslip faults moved mainly as normal faults, roughly perpendicular to the direction of compression, thereby reducing the intensity of regional tensional stress.

\section{Seismicity overview and earthquake data}

The delineation of tectonic domains in general and seismic source regions in particular, is a crucial step in seismic hazard assessment. The delineation of seismic sources and/or seismogenic sources is often dependent on detailed knowledge of the region and the availability of scientific data. Despite progress in developing procedures that reduce subjectivity in the delineation of areal seismogenic or seismic sources (e.g., Weatherill and Burton 2009; Ansari et al. 2015), substantial disparities remain. This is especially true, as noted by Beauval et al. (2006), for regions where faulting is either poorly known or inadequately characterized. Different experts may provide different maps that employ contrasting zonation schemes based on different interpretations of what little data are available.

Taking into account key developments in probabilistic seismic hazard assessment, such as the works of Cornell (1968), McGuire (1976), Kramer (1996), and Abrahamson (2006), our estimates consider all available geological and tectonic data related to the region. A wideranging survey of existing literature about the region was used to delineate the most important 
tectonic domains, taking well-known tectonic features and located seismicity into consideration.

Deformation in the Morocco-Algeria region is marked by the spectacular topography of the Atlas fault system, which underwent major active deformation during the Quaternary (Udías and Buforn 1991; Frizon de Lamotte et al. 2000; Gomez et al. 2000; Meghraoui and Pondrelli 2012). Indeed, kinematic models and tectonic studies of the region show that this area is subjected to 4-6 mm/year of crustal deformation (Nocquet and Calais 2004). As discussed by Meghraoui and Pondrelli (2012), the plate boundary is often represented by an E-W straight line extending to the Mediterranean coast, drawn along the foreland-hinterland limit of the Tertiary fold-and-thrust belt, or inferred from hypothetical tectonic blocks. Compressional movement between the two plates is responsible for the development of the large-scale Atlas fault-belt system, and regularly triggers major earthquakes.

In Morocco, as described by Meghraoui and Pondrelli (2012), the Rif tectonic domain can be divided into (1) the West Rif, characterized by NE-SW trending Pleistocene folding, strike-slip faults, and SW-verging fold-and-thrust nappes; and (2) the East Rif, characterized by overthrust structures and two main NE-SW trending left-lateral strike-slip faults. This region has experienced destructive earthquakes in the recent past, including the Al Hoceima earthquakes of 1994 and 2004 (Stich et al. 2005; Cakir et al. 2006; D'Acremont et al. 2014; Lafosse et al. 2016). The most recent event occurred on 25 January 2016, with magnitude $M w$ 6.3. Another domain, the Moroccan Meseta, is located to the south of the Rif mountain range, and is similar to the Algerian High Plateau. Seismicity is generally lower in the southern part of the Rif mountain range. On the other hand, diffuse seismicity is observed in the Atlas and Anti-Atlas mountains (Figure 1). Consequently, seismic activity decreases eastward along the High Atlas mountain range (Peláez et al. 2007; Hamdache et al. 2010). According to Peláez et al. (2007), the information on Moroccan Atlas seismicity indicates that the magnitudes of most events are below 5.0, but some larger events have occurred on the eastern margin of the Anti-Atlas. The largest earthquake recorded in the Atlas region, with intensity $I_{0} \approx X$, was the destructive 1960 Agadir earthquake. Nevertheless, the Atlas region is characterized by only moderate seismic activity.

Activity in northern Algeria is located mainly in the Tellian mountain range (Figure 1), characterized by frequent weak to moderate shallow earthquakes. According to Bezzeghoud and Buforn (1999) and Hamdache et al. (2010), events with magnitudes up to 
5.5-6.5 have been located close to Quaternary basins.

In Algeria, the western part of the Tellian Atlas includes a large continental Neogene and Quaternary basin, affected by NE-SW trending right-stepping en-echelon active folds. The Chelif Quaternary Basin and the associated El Asnam Fault have been the subject of several studies (Philip and Meghraoui 1983; Meghraoui et al. 1986). It is important to note that the El Asnam fault is active: it hosted the $M w 7.3$ earthquake of 10 October 1980. The central part of the Tellian Atlas includes the Algiers region, the capital of Algeria, and the Mitidja basin, which contains strongly folded Quaternary deposits (Beghoul et al. 2009; Meghraoui and Pondrelli 2012). The region has experienced several historic earthquakes, including the damaging $M w 6.8$ Zemmouri earthquake of 21 May 2003 (Hamdache et al. 2004, 2010). Different tectonic structures form the eastern Tellian Atlas: the Kabylia domain includes the high mountains of Djurdjura, contains thrusts and nappes, limits the Quaternary Soummam basin, and extends south to the High Plateau (Boudiaf et al. 1999). According to Hamdache et al. (2010), the region was the site of several weak to moderate earthquakes, which attest to the active deformation in this area. Tectonic forces in the eastern part of the region have resulted in right-lateral, pull-apart Neogene and Quaternary basins, in addition to the left lateral NE-SW faults and related seismicity. The most significant event in this region occurred on 27 October 1985, with magnitude Ms 5.9 (Meghraoui 1988). To the south, the Sahara region appears aseismic, apart from a few events along the Saharan Atlas mountain range in Algeria.

The earthquake data files used in this study were compiled by Peláez et al. (2007) and Hamdache et al. (2010) for northern Morocco and northern Algeria, respectively. Figure 1 shows the epicentral distribution of earthquakes with estimated magnitudes of at least $M w 4.0$.

In this study, the region of interest is divided into five large tectonic domains (Figure 2). The first zone is the Tell, which covers a large part of northern Algeria, including the Tell Atlas area and a large part of the continental margin. The second zone is the High Plateau, which is located to the south of the Tell Atlas area. The third zone is the Atlas, which includes the Tunisian Atlas, the Algerian Saharan Atlas, and the Moroccan High and Middle Atlas mountainous areas. Two others source zones are located in Morocco: the Moroccan Meseta, and the Rif Mountains and surrounding area. 


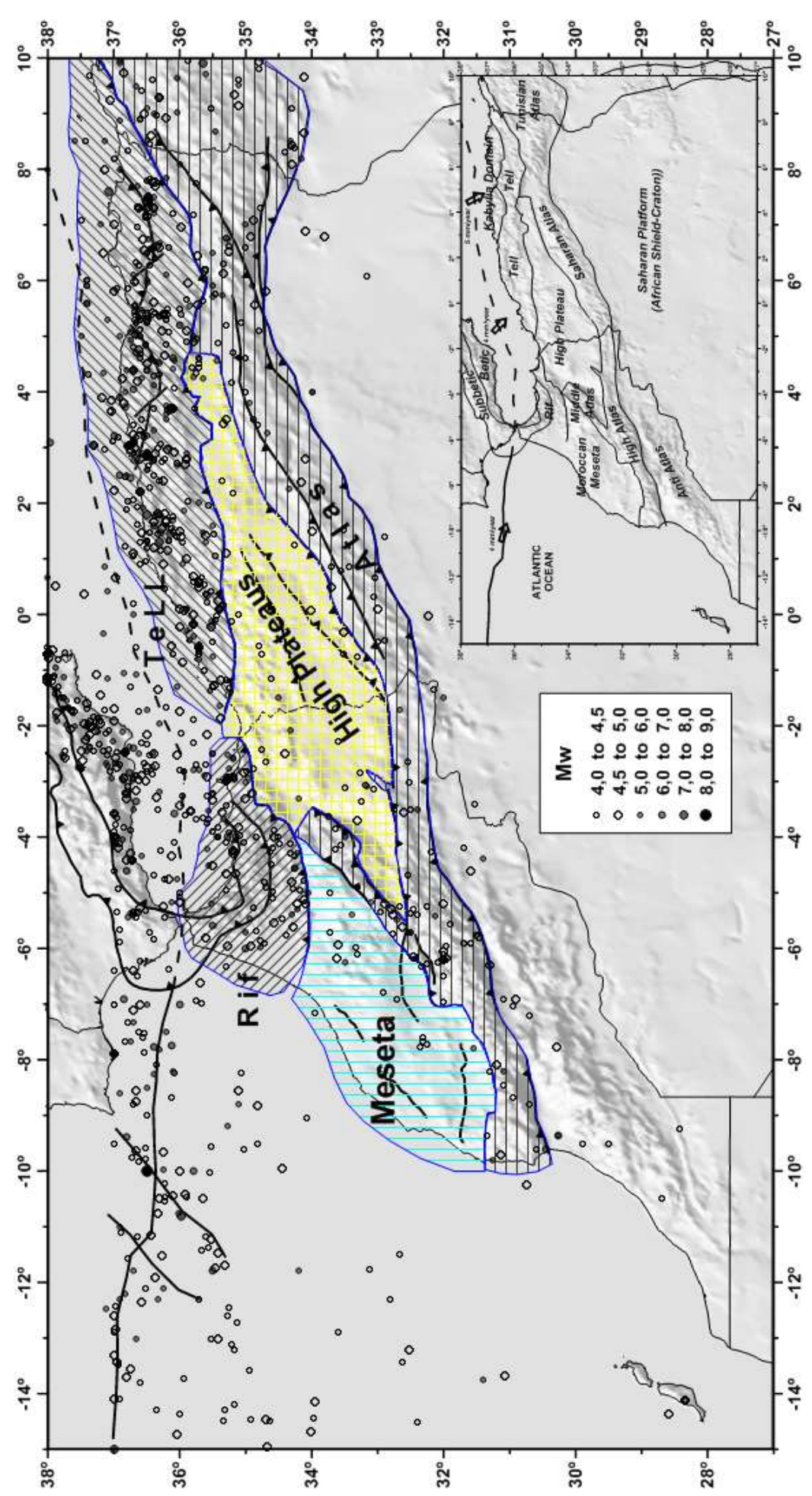

Figure 2: Proposed seismogenic source model, including the most important domains in the region.

\section{Gutenberg-Richter parameters}

The Gutenberg-Richter relationship was initially used to characterize our proposed zone model. We first employed the procedure of Weichert (1980) to estimate the mean seismic 
activity rate and $b$-values for each of the five seismogenic zones defined in Figure 2. Our assessments of these seismic parameters were then improved using the method of Kijko and Smit (2012). These two approaches were deemed the most appropriate to process the earthquake data compiled for this study, as the data necessarily include both historical and recent (instrumented) events. The maximum likelihood procedure of Weichert (1980) is based on grouping events into specified time and magnitude intervals. The technique of Kijko and Smit (2012) similarly applies a maximum likelihood estimator after dividing the earthquake catalog into different subcatalogs above a threshold magnitude. The estimated $b$-value obtained in this way constitutes an extension of the classical Aki-Utsu estimator (Aki 1965; Utsu 1965). Results obtained using each approach are discussed and compared below.

The earthquake catalog for this study was created by merging two earthquake catalogues compiled specifically for northern Morocco (Peláez et al. 2007) and northern Algeria (Hamdache et al. 2010). The Moroccan catalog covers the area bounded by $27^{\circ} \mathrm{N}-37^{\circ} \mathrm{N}$ and $15^{\circ} \mathrm{W}-1^{\circ} \mathrm{E}$ during the years $1045-2005$ A.D. The Algerian catalogue covers the area bounded by $32^{\circ} \mathrm{N}-38^{\circ} \mathrm{N}$ and $3^{\circ} \mathrm{W}-10^{\circ} \mathrm{E}$ during the years $856-2008$ A.D. For this assessment, the catalogues were merged and updated to June 2011, while carefully removing duplicates and non-crustal events (i.e., events with depths of $>30 \mathrm{~km}$ ). Figure 1 shows the epicentral distribution of events in our working catalog.

After preparing the earthquake catalog, we proceeded to identify and delete all nonPoissonian (dependent) events using the procedure of Gardner and Knopoff (1974), with space-time windows adapted to the study region. Using this method, the largest event within a particular space-time window is considered the main shock. In our catalog, for example, window sizes of 900 days and $100 \mathrm{~km}$ were used to identify aftershocks related to an $M w 8.0$ event (Peláez et al. 2007; Hamdache et al. 2010).

We now describe the seismic catalogue completeness magnitude, $m_{c}$; i.e., the minimum magnitude for reliable event detections. Several approaches have been developed to estimate $m_{c}$ (e.g., Wiemer 2001; Schorlemmer and Woessner 2008). Although historically it seems that the first procedure to perform completeness analysis was proposed by Stepp (1972), among the most widely used nowadays are the Maximum Curvature, Goodness of Fit, Entire Magnitude Range (Wiemer and Wyss 2000) and the Mean Base Slope (Amorese 2007) approaches. It is important to note that by using information about the detection capabilities and signal-to-noise ratios of seismic stations recording the events, others techniques have been developed to improve the reliability of catalog completeness magnitudes (e.g., Albarello 

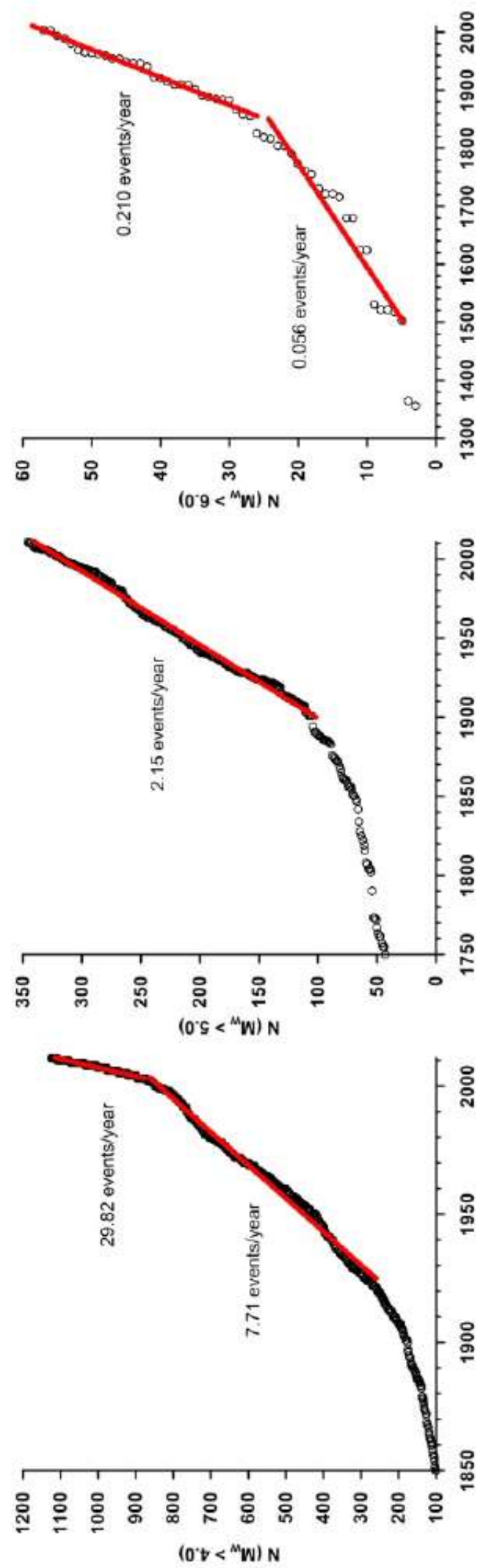

Figure 3: Cumulative number of earthquakes above magnitudes $M w 4.0,5.0$ and 6.0, obtained from the whole catalogue. 
et al. 2001; Schorlemmer and Woessner 2008). The choice of the most appropriate procedure for $m_{c}$ estimation depends on several factors, including the history of the seismic network, data collection, and processing.

In this study, analysis of the completeness magnitude and Poissonian character of the catalogue was performed using the cumulative number of events with magnitudes above a specified threshold. Figure 3 shows the cumulative number of earthquakes above $M w 4.0,5.0$, and 6.0. The stationarity of the rate is represented by the linearity in this figure; i.e., the whole catalogue can be considered complete above $M w 5.0$ from 1900, with a mean rate of 2.15 events/year, and above magnitude $M w 6.0$ after 1885, with a mean rate of 0.21 events/year. The catalog of earthquakes above $M w 4.0$ can only be considered complete since 2003, with a mean rate of 29.82 events per year; during the period 1925-2003, the mean rate of these events was only 7.71/year. Because the study region was not well covered by the Moroccan and Algerian seismic networks, many earlier earthquakes were detected by the Spanish National Geographic Institute network, which introduces a geographic bias against detections in the southern and eastern parts of the region (Peláez et al. 2007; Hamdache et al. 2010; Hamdache et al. 2012). This explains why the earthquake data could be considered complete above $M w 4.0$ after 1925 .

The Gutenberg-Richter law describes the relationship between earthquake magnitude and the estimated frequency of earthquake occurrence. In its standard form, it is written

$$
\log _{10} N(m)=a-b m, m_{c} \leq m \leq m_{\max },
$$

where $N(m)$ is the cumulative number of events with magnitude $\geq m$, and the parameters $a$ and $b$ are positive constants.

The $a$-parameter describes the seismic activity level, and depends on the size of the source region and the observation period. It is commonly the case, as in Scholz (2015), that the parameter $a$ is succinctly said to describe the total number of earthquakes.

The parameter $b$, often referred to as the $b$-value, describes the relative size distribution of earthquakes. In general, the $b$-value reflects the ratio between large and small earthquakes, and it is related to the stress conditions in the region (Mogi 1962). In addition, some researchers link the $b$-value with the parameters of the rupture process; for example, Schorlemmer et al. (2005) showed that $b$-values are dependent on faulting style. As pointed out by Amitrano (2012), based on laboratory experiments using brittle rocks, $b$-values depend on mechanical loading, type of faulting, confining pressure, and the roughness of the fault 
sliding surfaces. These observations agree with the idea that $b$-values are dependent on friction and/or mean stress; the distinction between these two factors remains difficult because they are correlated, as friction decreases when confining pressure increases (Goebel et al. 2012). Generally, $b$ varies between 0.6 and 1.4 for earthquakes generated by tectonic stresses (Utsu 1965; Wiemer and Katsumata 1999). Nevertheless, in hydraulic fractures and volcanic swarms, $b$-values routinely exceed 1.4 (Okubo, 1994; Wyss et al. 2001). Estimation of $b$ values is not straightforward, and can be biased for many reasons; for example, a leastsquares procedure introduces systematic errors (Marzocchi and Sandri 2003; Sandri and Marzocchi 2007). They arise from biases introduced by discretizing magnitudes into bins of with 0.1, as discussed in Marzocchi and Sandri (2003).

The fractal dimension $D_{2}$ characterizes the spatial distribution of seismic events, and is controlled by both the heterogeneity of the stress field and pre-existing geological, mechanical, and structural features (Öncel et al. 1996). It is generally accepted that seismicity is a classic example of a complex phenomenon that can be characterized by the formalism of fractals (Turcotte 1997). The $D_{2}$-value is an extension of the Euclidian dimension, and it measures the degree of spatial clustering of earthquakes. In a two-dimensional space, $D_{2}$ ranges from 0.0 to 2.0 (Spada et al. 2011). In this study, the spatial properties of each seismogenic source zone were analyzed by calculating the correlation integral. According to Grassberger and Procaccia (1983), the correlation integral

$$
C(r)=\frac{1}{N^{2}} \sum_{i=1}^{N} \sum_{j=1}^{N} H\left(r-\left|e_{i}-e_{j}\right|\right)
$$

describes the spatial distribution of $N$ earthquakes, where $\mathrm{N}$ is the number of points in the analysis window, $\left(\theta_{i}, \phi_{i}\right)$ are the epicentral coordinates of event $e_{i}$, and $\mathrm{H}$ is the Heaviside step function. $C(r)$ is equivalent to the probability that two points can be separated by a distance less than $r$. The angular distance $\mathrm{X}$ in degrees between events $\left(\theta_{i}, \phi_{i}\right)$ and $\left(\theta_{j}, \phi_{j}\right)$ is estimated using the formula

$$
X=\cos ^{-1}\left[\cos \theta_{i} \cos \theta_{j}+\sin \theta_{i} \sin \theta_{j} \cos \left(\phi_{i}-\phi_{j}\right)\right]
$$

(Hirata 1989), where $i, j$ are event indices and $\theta, \phi$ are latitude and longitude, respectively. The correlation integral is theoretically proportional to the power of $D_{2}$; i.e., $C(r) \approx r^{D_{2}}$, where $r$ is a linear approximation of the angular distance $X$. The fractal dimension $D_{2}$ is then given by 


$$
D_{2}=\lim _{r \rightarrow 0} \frac{\log _{10} C(r)}{\log _{10}(r)}
$$

Following the method of Spada et al. (2011), $D_{2}$-values were estimated using a least-squares technique in this work, with the same data set as used to estimate $b$-values.

The fractal dimension is often used to quantify the degree of heterogeneity of the seismic activity of a fault system or region. According to Öncel and Wilson (2002), a decrease in $D_{2}$ generally corresponds to an increasing degree of event clustering. However, for large values of $r$, the $\log -\log$ plot of the empirical value of $C(r)$ is artificially low; for small values of $r$, the value is unnaturally high. These two cases are known as saturation and depopulation (Nerenberg and Essex 1990). To detect and eliminate depopulation and saturation effects, the range of distances used is defined within the region where the $\log -\log$ plot is stable. The stability of the $\log -\log$ plot of the empirical value of $C(r)$ is verified by calculating the first derivative between each pair of empirical $C(r)$ values and plotting the result against the logarithm of distance.

We used the procedure of Weichert (1980) to derive the $b$-value and fractal dimension $D_{2}$ for each proposed tectonic domain. Figure 4 shows the results, including the best-fit straight line for each plot. The values obtained for each area are also listed in Table 1. The mean seismic activity rates for magnitudes $M w>4.0$ were normalized to 10 year intervals and square cell with a $100 \mathrm{~km}$ side. Accordingly, the estimated mean activity rate in the Tell seismogenic zone, as normalized to a cell with a $100 \mathrm{~km}$ side and 10 years long, is 2.62 earthquakes. The activity rates for the Rif and the Atlas zones are 1.91 and 0.72 earthquakes per decade and per square cell with $100 \mathrm{~km}$ side, respectively. The lowest activity rates are 0.23 and 0.35 earthquakes per decade and per $10000 \mathrm{~km}^{2}$, obtained in the Meseta and the High Plateau zones, respectively. The $b$-value and $D_{2}$ value are indirectly controlled by tectonic stress levels, which influence the seismicity rate and degree of clustering (Scholz 1968; Öncel et al. 1996). The relationship between the $b$-value and $D_{2}$ has been investigated thoroughly (e.g., Hirata 1989; Öncel and Wilson 2002); Bayrak and Bayrak (2012) used $D_{2} / b$ as an indicator of the earthquake hazard. According to Table 1, this parameter suggests that the Meseta, High Plateau, and Atlas zones are low-stress areas, characterized by lower seismic hazards than other regions. The Rif and Tell zones, which are characterized by high levels of tectonic stress, should be considered areas of high seismic hazard where strong earthquakes can occur. 
Table 1: $b$-value of the Gutenberg-Richter relationship, obtained by using the Weichert (1980) procedure. The fractal dimension and the seismic activity rate above magnitude $\mathrm{Mw} 4.0$ normalized to decade and to $100 \mathrm{~km}$ square side cell.

\begin{tabular}{|c|c|c|c|c|}
\hline & $b \pm \sigma_{b}$ & $D_{2} \pm \sigma_{D_{2}}$ & $D_{2} / b$ & $\begin{array}{c}\text { Mean Seismic } \\
\text { activity }\end{array}$ \\
\hline Atlas & $1.04 \pm 0.04$ & $1.11 \pm 0.04$ & 1.06 & 0.72 \\
\hline Meseta & $0.93 \pm 0.10$ & $1.32 \pm 0.03$ & 1.41 & 0.23 \\
\hline H.Plateaux & $0.72 \pm 0.03$ & $1.14 \pm 0.05$ & 1.58 & 0.35 \\
\hline Rif & $0.87 \pm 0.02$ & $1.85 \pm 0.07$ & 2.12 & 1.91 \\
\hline Tell & $0.77 \pm 0.02$ & $1.61 \pm 0.02$ & 2.09 & 2.62 \\
\hline
\end{tabular}

It deserves to point out that some recent works have attempted to improve the estimation of the Gutenberg-Richter parameters. For example, Marquez-Ramirez et al. (2015) explored the effects of magnitude rounding and the presence of noise in rounded magnitudes; they proposed a straightforward procedure to derive the correct mean of the rounded magnitudes used in the Aki-Utsu $b$-value estimation.

The method of Kijko and Smit (2012) was used to extend the Aki-Utsu $b$-value estimator by taking into account the specificity of the earthquake catalog, which includes both historical and instrumental data. To implement the procedure, we divided the earthquake catalog for each area into a historical part and a complete part, and computed a threshold magnitude for each part independently (Table 2). The estimated seismic hazard parameters for each domain are listed in Table 3. This procedure allowed us to estimate the annual activity rate of events with magnitudes equivalent to $M w>4.0$. The last column of Table 3 shows normalized activity rates (per decade and per $100 \mathrm{~km}$ square cell size).

Bearing in mind the age of the earliest historic records, a catalog based on instrumental data alone is not as complete as desired, yet there are often deficits in historic data, so the latter must be considered incomplete. The use of incomplete catalogues has been discussed previously (Molchan et al. 1970; Weichert 1980; Kijko and Sellevoll 1989, 1992; Rosenblueth 1986; Rosenblueth and Ordaz 1987). Generally the results of Seismic Hazard Analysis including Gutenberg-Richter relationship are highly influenced by input data that mathematically appear in the $b$-value, maximum magnitude and occurrence rate. Thus, using incomplete catalogue may influence the accuracy and the reliability of such results. 
Table 2: Historical part and complet subcatalogs for each zone used in the calculation using the Kijko and Smit (2012) procedure.

Historical and instrumental parts of the file

\begin{tabular}{|c|c|c|c|c|c|}
\hline & Atlas & Meseta & H. Platx & Rif & Tell \\
\hline Nbre events & 150 & 18 & 40 & 97 & 341 \\
\hline$m_{\max }^{o b s}$ & 6.3 & 5.2 & 5.7 & 6.4 & 7.3 \\
\hline Hist. part & - & - & - & - & $\begin{array}{c}1840-1909 \\
5.2\end{array}$ \\
\hline Comp1 & $\begin{array}{c}1910-1959 \\
4.5\end{array}$ & $\begin{array}{c}1970-2011 \\
4.0\end{array}$ & $\begin{array}{c}1913-2011 \\
4.0\end{array}$ & $\begin{array}{c}1790-2011 \\
4.0\end{array}$ & $\begin{array}{c}1910-1959 \\
4.4\end{array}$ \\
\hline Comp2 & $\begin{array}{c}1960-2011 \\
4.0\end{array}$ & - & - & - & $\begin{array}{c}1960-2011 \\
4.0\end{array}$ \\
\hline
\end{tabular}

Table 3: $b$-value of the Gutenberg-Richter relationship, obtained by using the Kijko and Smit (2012) procedure. $M_{\min }$ is the minimum magnitude, $\lambda_{m \text { min }}$ the annual activity rate for magnitudes above $M_{\min }$, and $\lambda_{\text {norm }}$ is the normalised activity rate per decade and per $100 \mathrm{~km}$ square cell size.

\begin{tabular}{|c|c|c|c|c|c|}
\hline \multirow[b]{2}{*}{ zone } & \multicolumn{5}{|c|}{$b$-value } \\
\hline & Period & $M_{\min }$ & $\lambda_{m \text { min }} \pm \sigma_{\lambda}$ & $b \pm \sigma_{b}$ & $\lambda_{\text {norm }} \pm \sigma_{\lambda}$ \\
\hline Atlas & $1910-2011$ & 4.0 & $1.79 \pm 0.37$ & $0.80 \pm 0.09$ & $0.73 \pm 0.15$ \\
\hline Meseta & $1970-2011$ & 4.0 & $0.43 \pm 0.15$ & $0.80 \pm 0.08$ & $0.43 \pm 0.14$ \\
\hline H. Plateaus & $1913-2011$ & 4.0 & $0.40 \pm 0.12$ & $0.89 \pm 0.22$ & $0.30 \pm 0.09$ \\
\hline Rif & $1790-2011$ & 4.0 & $0.42 \pm 0.12$ & $0.70 \pm 0.10$ & $0.69 \pm 0.19$ \\
\hline Tell & $1840-2011$ & 4.0 & $3.13 \pm 0.57$ & $0.70 \pm 0.05$ & $1.90 \pm 0.24$ \\
\hline
\end{tabular}

\section{Formalism for estimation of the maximum regional earthquake magnitude}

This section presents an overview of the methods used to estimate the maximum earthquake magnitude for each tectonic domain. This parameter is needed by the earthquake engineering community, disaster management agencies, and the insurance industry. In the context of this work, it is also a reliable indicator of the energetic potential of regional seismicity.

According to Kijko (2004), Kijko and Singh (2011), and Holschneider et al. (2011), the maximum regional magnitude $m_{\max }$ is defined as the expected upper magnitude limit for a given region. Several authors have published studies on the subject, including Kijko and Sellevoll (1989, 1992), Pisarenko (1991), Pisarenko et al. (1996), Kijko and Graham (1998), Kijko (2004), Kijko and Singh (2011), and Holschneider et al. (2011). 
Generally, two main approaches for $m_{\max }$ evaluation can be found in the literature, based on deterministic and probabilistic methodologies, respectively. The former use empirical relationships between magnitudes and various tectonic and fault parameters, as discussed in detail by Wells and Coppersmith (1994), Wheeler (2009), and Mueller (2010). However, using deterministic approaches the uncertainties in $m_{\max }$ estimation are, in most cases subjective, and can exceed one unit of magnitude per moment.

Several statistical procedures for estimating $m_{\max }$ can be found in Kijko (2004) and Kijko and Singh (2011). All are based on the assumption that earthquake magnitudes are independent, identically distributed (i.i.d.) random variables, described by a probability density function (PDF) $f_{M}(m)$ or a cumulative distribution function (CDF) $F_{M}(m)$. The maximum regional earthquake magnitude $m_{\max }$ is considered the upper limit of the magnitude distribution. It is important to note that these procedures do not rely on subjective assumptions. They provide generic solutions that depend on rational assumptions about the statistical model and knowledge of past seismic activity. According to Kijko (2004) and Kijko and Singh (2011), these procedures can be grouped into parametric and non-parametric methods; e.g., fitting a CDF based on earthquake magnitudes. Following Kijko (2004) and Kijko and Singh (2011), parametric procedures are used when the $a$ - and $b$-values of the frequency-magnitude distribution are known. These methods are based on the principle that $m_{\max }=m_{\max }^{o b s}+\Delta$, where $m_{\max }^{o b s}$ is the largest observed earthquake magnitude in the area, and $\Delta$ is a positive correction factor.

We use four test procedures to assess the maximum regional magnitude for each area. First, we consider the simplest possible form for the correction factor,

$$
\Delta=\left[n f_{M}\left(m_{\max }^{o b s}\right)\right]^{-1}
$$

where $n$ denotes the number of earthquakes. Although this method was first introduced by Tate (1959) for estimating $m_{\max }$, the form above was first used explicitly by Pisarenko et al. (1996). Applied to the Gutenberg-Richter law, this takes the form

$$
m_{\max }=m_{\max }^{o b s}+\frac{1-\exp \left[-\beta\left(m_{\max }-m_{\min }\right)\right]}{n \exp \left[-\beta\left(m_{\max }^{o b s}-m_{\min }\right)\right]}
$$


where $\beta=b \ln (10)$ (Kijko and Graham 1998; Kijko 2004; Kijko and Singh 2011). The value of $m_{\max }$ obtained from the iterative solution of equation (6) is referred to as the TatePisarenko estimator of $m_{\max }$ (in short, the T-P estimator).

The second estimator considered takes the form

$$
m_{\max }=m_{\max }^{o b s}+\frac{E_{1}\left(n_{2}\right)-E_{1}\left(n_{1}\right)}{\beta \exp \left(-n_{2}\right)}+m_{\min } \exp (-n)
$$

where $n_{1}=1 /\left\{1-\exp \left[-\beta\left(m_{\max }-m_{\min }\right)\right]\right\}, n_{2}=n_{1} \exp \left[-\beta\left(m_{\max }-m_{\min }\right)\right]$, and $E_{1}$ denotes the exponential integral function (Abramowitz and Stegun 1970). This technique was introduced by Kijko and Sellevoll (1989), and herein is referred to as the K-S estimator. Because the desired $m_{\max }$ appears on both sides of the above equation, estimated values of $m_{\max }$ and $\hat{m}_{\max }$ can be obtained through iteration. Kijko and Graham (1998) showed that $m_{\max }$ estimated with this technique have substantially lower mean squared error values than estimates obtained using the T-P approach.

The next two estimators tested are extensions of the T-P and $\mathrm{K}-\mathrm{S}$ estimators, which account for uncertainty in earthquake magnitude distributions. Kijko and Singh (2011) showed that representing temporal variations in the $b$-value by a Gamma distribution with parameters $p$ and $q$ yields the following modified equations for the T-P and $\mathrm{K}-\mathrm{S}$ estimators:

$$
\begin{gathered}
m_{\max }=m_{\max }^{o b s}+\frac{1}{n \bar{\beta} C_{\beta}}\left(\frac{p}{p+m_{\max }^{o b s}-m_{\min }}\right)^{-(q+1)} \\
m_{\max }=m_{\max }^{o b s}+\frac{\delta^{1 / q} \exp \left[n r^{q} /\left(1-r^{q}\right)\right]}{\beta}\left[\Gamma\left(-1 / q, \delta r^{q}\right)-\Gamma(-1 / q, \delta)\right]
\end{gathered}
$$

where $C_{\beta}=\left(1-r^{q}\right)^{-1}, r=p /\left(p+m_{\max }-m_{\min }\right), p=\bar{\beta} /\left(\sigma_{\beta}\right)^{2}, q=\left(\bar{\beta} / \sigma_{\beta}\right)^{2}, \bar{\beta}$ is the mean $\beta$ value, $\sigma_{\beta}$ is the standard deviation of the $\beta$-value fluctuations, $\delta=n C_{\beta}$, and $\Gamma$ is the complementary incomplete Gamma function. As before, these modified equations do not directly provide estimators of $m_{\max }$; thus, $m_{\max }$ must be computed by iteration. Since these compound distributions are often incorrectly termed Bayesian distributions (Campbell 1982), the solution to equation (8) is called the Tate-Pisarenko-Bayes estimator of $m_{\max }$ (T-P-B estimator), and the solution to equation (9) is called the Kijko-Sellevoll-Bayes estimator (KS-B estimator). 
The previous procedures allow us to derive a reliable magnitude distribution, then to construct an upper confidence limit. A $100(1-\alpha) \%$ upper limit of $m_{\max }$ can be estimated from $P\left(m_{\max }<F_{M}^{-1}(m)\right)=1-\alpha$, where $F_{M}^{-1}(m)$ denotes the inverse CDF of $F_{M}(m)$.

\section{Estimates of the maximum regional magnitude}

The above procedures were used to estimate the maximum possible magnitude in each seismogenic zone defined in Figure 2. An earthquake catalog for each studied area was extracted from the compiled regional catalog; Table 2 lists the number of events, the maximum observed magnitude $m_{\max }^{o b s}$, and the completeness magnitude $m_{c}$ for each regional subcatalog. For all catalogues, we assumed a mean error of approximately 0.3 units for recorded magnitudes (Peláez et al. 2007; Hamdache et al. 2010).

Table 4: Maximum regional magnitude and its standard deviation, derived by using the parametric procedures. T-P, K-S, T-P-B and K-S-B are the Tate-Pisarenko, Kijko-Sellevoll, and their corresponding Bayesian version estimators.

\begin{tabular}{|c|c|c|c|c|}
\hline & \multicolumn{4}{|c|}{ Estimated $m_{\max }$} \\
\hline & T-P & $\mathrm{K}-\mathrm{S}$ & T-P-B & K-S-B \\
\hline Atlas & $6.50 \pm 0.36$ & $6.45 \pm 0.34$ & $6.46 \pm 0.34$ & $6.43 \pm 0.33$ \\
\hline Meseta & $5.44 \pm 0.39$ & $5.38 \pm 0.35$ & $5.43 \pm 0.38$ & $5.37 \pm 0.34$ \\
\hline H. Plateaus & $5.77 \pm 0.31$ & $5.76 \pm 0.31$ & $5.77 \pm 0.31$ & $5.76 \pm 0.31$ \\
\hline Rif & $6.87 \pm 0.55$ & $6.64 \pm 0.38$ & $6.70 \pm 0.42$ & $6.60 \pm 0.36$ \\
\hline Tell & $7.50 \pm 0.36$ & $7.46 \pm 0.34$ & $7.45 \pm 0.33$ & $7.43 \pm 0.33$ \\
\hline
\end{tabular}

Estimates for $m_{\max }$ obtained using the four parametric techniques are listed in Table 4. Our implementation of each procedure assumes that the data are well characterized by a linear Gutenberg-Richter relationship. The maximum regional magnitude estimates obtained using each parametric procedure show a good degree of consistency. The $\mathrm{K}-\mathrm{S}$ procedure gives similar results for each seismogenic zone (Table 4). The estimated maximum magnitude values are equal to $6.4 \pm 0.3,5.4 \pm 0.4,5.8 \pm 0.3$, and $6.6 \pm 0.4$ for the Atlas, Meseta, High Plateau, and Rif zones, respectively. In the Tell, the maximum expected magnitude of $7.5 \pm$ 0.4 might be because this region accommodates most of the deformation resulting from collision of the Eurasian and African plates. Using parametric methods,_estimates of $m_{\max }$ vary 
Table 5: Confidence limits for the maximum regional magnitude, obtained by using the Kijko-Sellevoll (K-S) parametric estimator and its Bayesian version (K-S-B).

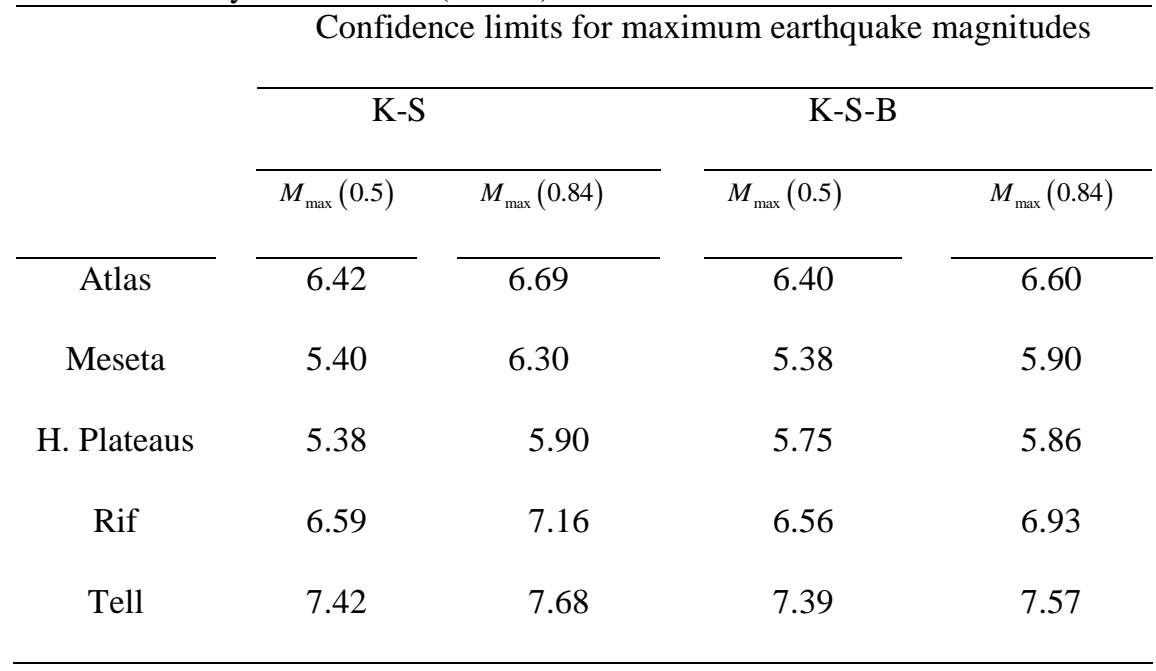
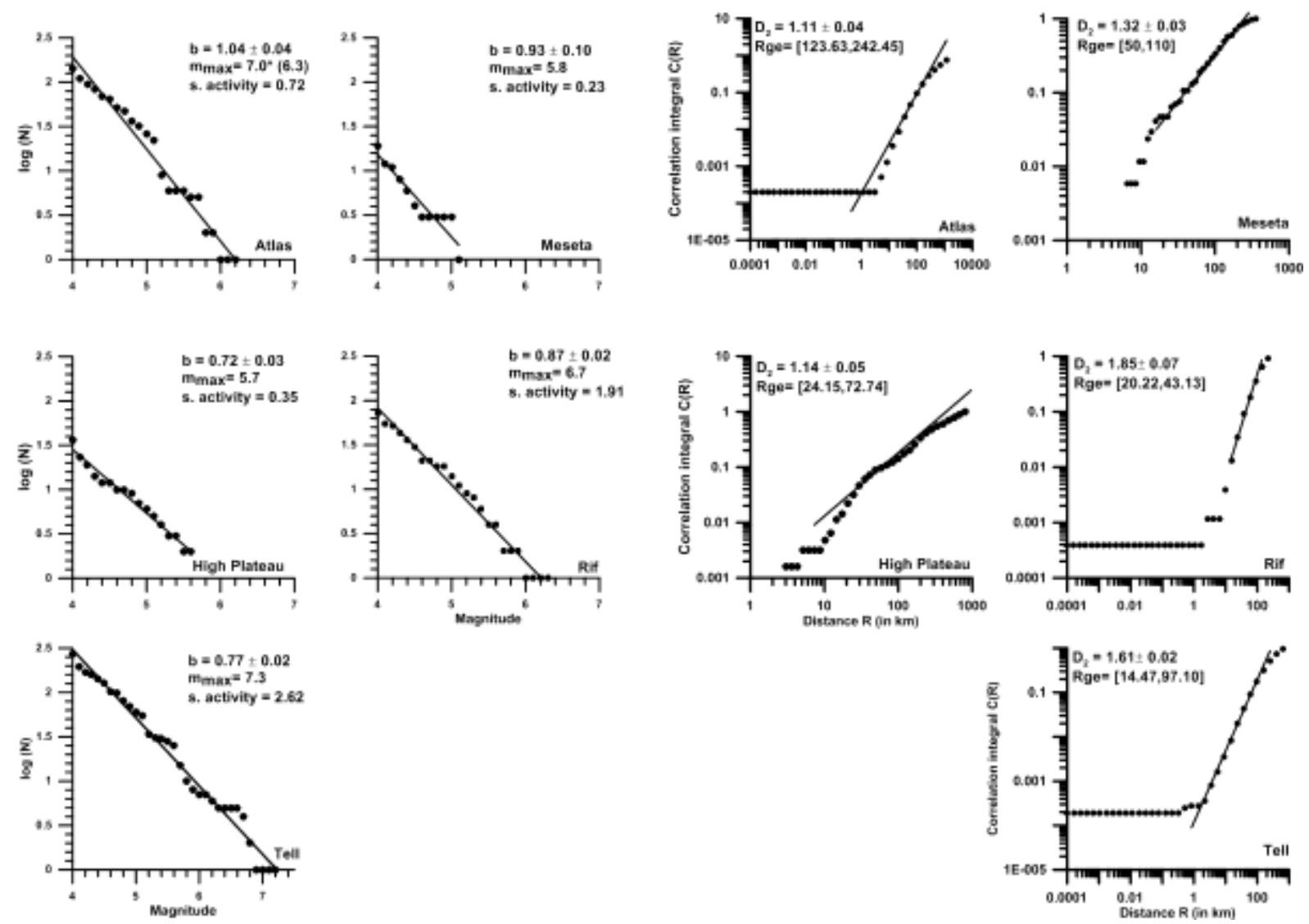

Figure 4: Map showing the plot of the Gutenberg-Richter fit and the plots of, $\log _{10} C(r)$ vs. $\log _{10}(r)$ as well as the straight fit data for each seismogenic zone.

between $7.4 \pm 0.3$ and $7.5 \pm 0.4$ which suggests accurate estimates. As mentioned previously, this zone has experienced what are considered to be the most damaging earthquakes in the region (i.e., the 1954 and $1980 \mathrm{El}$ Asnam earthquakes, and the 2003 Zemmouri earthquake). 
Table 5 lists the $50 \%$ and $84 \%$ confidence limits of the maximum regional earthquake magnitudes, obtained using the $\mathrm{K}-\mathrm{S}$ and $\mathrm{K}-\mathrm{S}-\mathrm{B}$ approaches.

Seismic activity in this region can be defined as low to moderate. Using the Weichert approach, we obtain an average of 2.62 earthquakes per year with $M w>4.0$ and per square cell with $100 \mathrm{~km}$ sides (Figure 4). The normalized activity rate above $M_{w} 4.0$, obtained using the Kijko and Smit (2012) approach, is $\lambda_{\text {norm }}=1.90 \pm 0.24$ (Table 3). The values listed in Table 3 confirm that the Tell area is the most active of the five domains.

Considering that the $\mathrm{K}-\mathrm{S}$ procedure provides a consistent assessment of $m_{\max }$ for each seismogenic zone, the respective probabilities of exceedance of specified magnitudes and return periods can be calculated from this technique. Figure 5 displays plots of the return
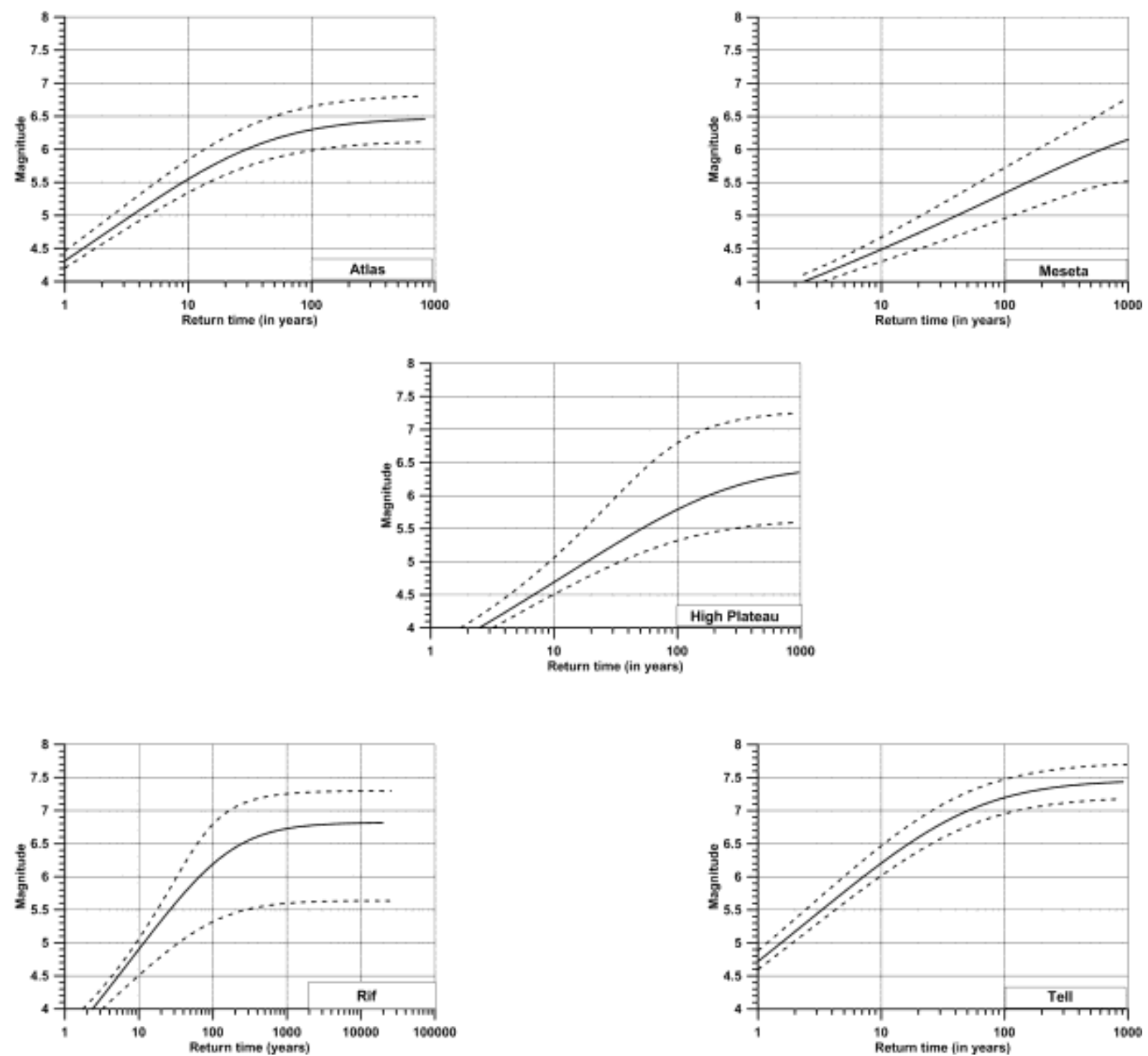

Figure 5: Plot of the mean return time for magnitudes above $M w 4.0$ (solid line), including its standard deviation (dashed line). 
periods of earthquakes with $M w 4.0$ to $m_{\max }$ for each seismic region. The mean return period is shown as a solid line, and its uncertainty is indicated by a dashed line. On average, an event with a magnitude exceeding 5.0 occurs approximately once every $3.5,1.5,11.5,18.5$, and 41 years, and an event with magnitude exceeding 6.0 occurs approximately once every $30,7.2$, 66, 178.7, and 610 years in the Atlas, Tell, Rif, High Plateau, and Meseta zones, respectively. Accurate estimates of the mean return periods for different magnitude values are important in estimating seismic hazard and risk. These estimates can form an empirical basis for seismic building codes, to which specifications for different categories of building (normal, strategic,
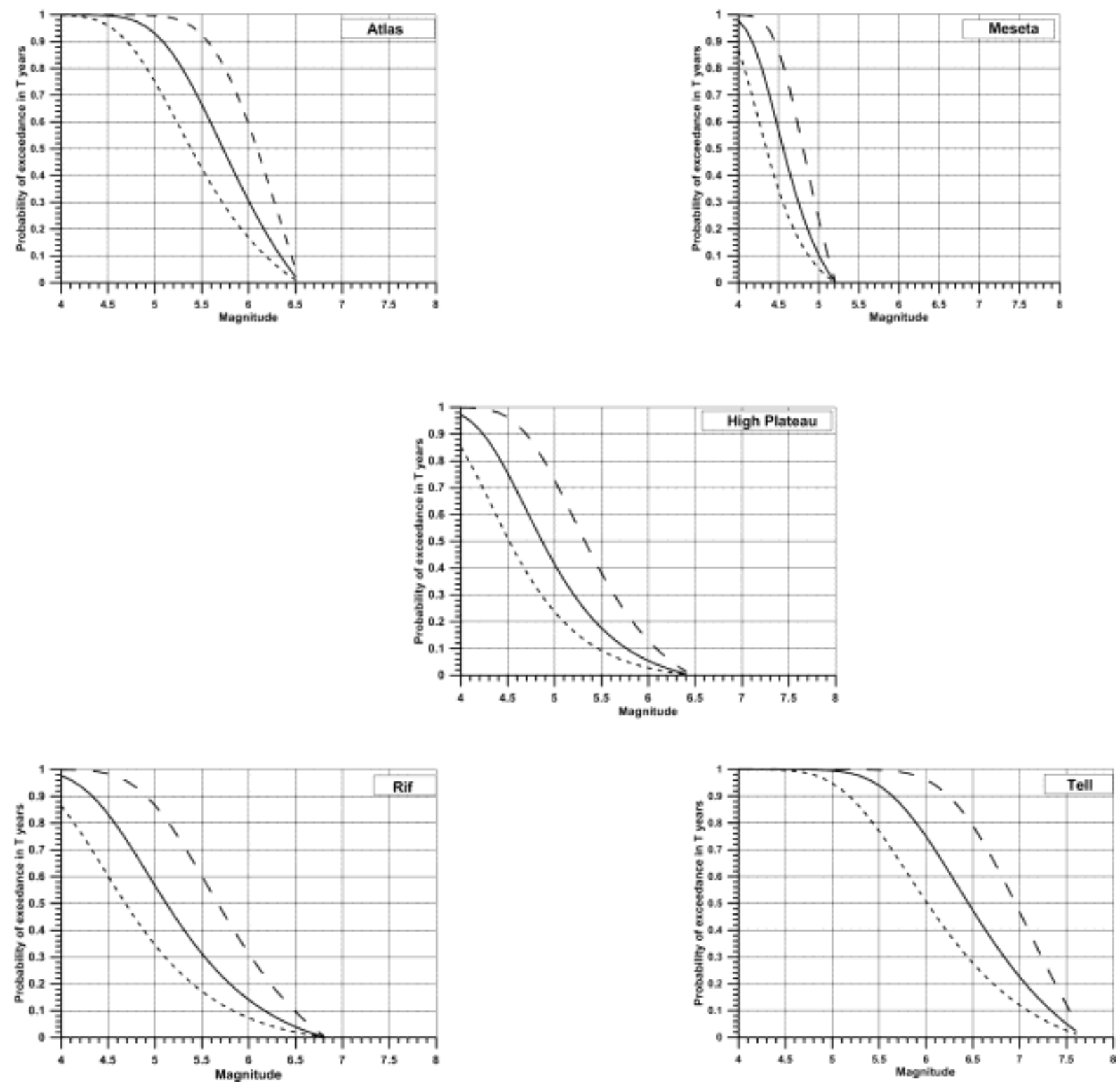

Figure 6: Probability of exceedence in $\mathrm{T}=5$ (dashed line), 10 (solid line) and 25 (large dashed line) years for magnitudes above $M w 4.0$ in each source zone. 
and monumental) should conform, and they determine the priority queues for retrofitting of existing buildings. These results indicate that the Tell region is of greatest concern.

On the other hand, these procedures have allowed us to estimate the probability of exceedance of at least one specified magnitude value within each specified time interval $T$. The obtained results for $T=5,10$, and 25 years, shown in Figure 6, indicate that, for example, in the Tell area the probability of at least one event with $M w>5.0$ in a given 10 year interval is 0.99 . These results agree very well with those obtained by Peláez et al. $(2012,2016)$.

\section{Discussion and conclusion}

In this study, we used several tools to analyze key energetic and spatial features of seismicity in the Algeria-Morocco region. As mentioned previously, this region experienced several damaging earthquakes in the past. This emphasizes the importance of obtaining reliable information to anticipate and mitigate destructive events, including seismic risk assessment for urban areas. We defined five seismogenic source zones within the Algeria-Morocco region based on available geological and seismic data, including well-known tectonic domains and located seismicity. Our analysis included seismic catalogues for northern Morocco and northern Algeria updated through 2011. For each zone, the parameters of the Gutenberg-Richter law were estimated using the procedures of Weichert (1980) and Kijko and Smit (2012). The seismicity of each source zone was expressed in terms of the seismic activity rate, normalized to 10 year windows and square cell with $100 \mathrm{~km}$ sides. Of the five defined tectonic domains, the Tell zone appears to be the most active and has the highest estimated hazard, with a mean activity rate, normalized to decade and square cell of 10,000 $\mathrm{km}^{2}$, equal to $2.62 \mathrm{Mw}>4.0$ earthquakes. For each defined domain, the fractal dimension $\mathrm{D}_{2}$ was estimated using the correlation integral $C(r)$. Following Pailoplee et al. (2014), the tectonic context of the ratio $D_{2} / b$ is that the Rif and Tell regions accumulate the highest levels of tectonic stress, and therefore exhibit the greatest risk of large earthquakes. The Meseta, High Plateau, and Atlas zones are low-stress zones, with lower seismic activity rates and hazards than the other regions.

In general, the $b$-value estimates do not significantly differ from $b$-values already computed in previous investigations (Peláez et al. 2012; 2016). The Tell region appears to be the most active, with a normalized activity rate of $1.90 \pm 0.24 M w>4.0$ events. Lower values, of $0.30 \pm 0.09$ and $0.43 \pm 0.14$, are obtained for the High Plateau and Meseta zones, 
respectively. The Atlas zone displays a normalized annual activity rate of $0.73 \pm 0.15 \mathrm{Mw}$ $>4.0$ events. The $m_{\max }$ value computed for each zone was used to assess the energetic potential using several techniques.

For the Tell and Rif source zones, where earthquake catalogues are regarded as the most complete and accurate, the parametric estimation procedures for $m_{\max }$ provided the most reliable and internally consistent results. However, in instances where the data were incomplete and uncertain, non-parametric procedures based on the largest events must be used.

Finally, this study allowed us to derive parameters for the "seismic potential" of the delineated tectonic domains, mainly comprising estimates of maximum possible regional magnitude, spatial clustering characteristics, and distribution of seismicity.

Acknowledgments: We thank the Editor-in-Chief Thomas Glade, Guest Editor Sebastiano D'Amico, and two anonymous reviewers for thoughtful comments. This research was supported by the Algerian CRAAG, the Spanish Seismic Hazard and Active Tectonics research group, and the Spanish MINECO CGL2015-65602-R project.

\section{References}

Abrahamson, N. 2006. Seismic hazard assessment: problems with current practice and future developments, in First European Conference on Earthquake Engineering and Seismology, Geneva, Switzerland.

Abramowitz, M., and I. A. Stegun. 1970. Handbook of Mathematical Functions ( $9^{\text {th }}$ ed.), Publ. New York.

Aki, K. 1965. Maximum likelihood estimates of $b$ in the formula $\log N=a-b m$ and its confidence limits. Bull. Earthq. Res. Inst. Tokyo Univ. 43, 237-239.

Albarello, D., Camassi, R., and A. Rebez. 2001. Detection of Space and Time Heterogeneity in the Completeness of a Seismic Catalog by a Statistical Approach: An Application to the Italian Area. Bull. Seism. Soc. Am., 91:1694-1703

Amitrano, D. 2012. Variability in the power-law distribution of rupture events. How and why does $b$-value change? European Physical Journal Special Topics, 205 (1), 199-215

Amorese, D., 2007. Applying a Change Point Method on Frequency-Magnitude Distribution. Bull. Seism. Soc. Am., 97: 1742-1749

Ansari, A., E. Firuzi and L. Etemadsaeed. 2015. Delineationof seismic sources in Probabilistic Seismic-Hazard Analysis Using Fuzzy cluster Analysis and Monte Carlo Simulation. Bull. Seism. Soc. Am. Vol. $105, n^{\circ} 4$.

Bayrak, Y., and E. Bayrak. 2012. Regional variations and correlations of Gutenberg-Richter parameters and fractal dimension for the different seismogenic zones in Western Anatolia. J Asian Earth Sci. 58:98-107. 
Beauval, C., O. Scotti., and F. Bonilla. 2006. The role of seismicity models in probabilistic seismic hazard estimation; comparison of zoning and a smoothing approach, Geophys. J. Int., 165, 584-595.

Beghoul, N., J. L. Chatelain, M. Boughacha, H. Benhallou, R. Dadou and A. Mezioud-Saich. 2009. Seismic Empirical Relations for the Tellian Atlas, North Africa, and their Usefulnessfor Seismic Risk Assessment. Pure and Applied Geophysics, Basel/Switzerland DOI 10.1007/s00024-009-0018-z

Bezzeghoud, M., Buforn, E. 1999. Source parameters of the 1992 Melilla (Spain, Mw=4.8), 1994 Alhoceima (Morocco, Mw=5.8) and 1994 Mascara (Algeria, Mw=5.7) earthquakes and seismotectonic implications. Bull. Seism. Soc. Am. 89, 359-372.

Buforn, E., M. Bezzeghoud, A. Udias and C. Pro. 2004. Seismic Sources on the Iberia -African Plate Boundary and their Tectonic Implications, Pure Appl. Geophys., 161, 1- 24.

Boudiaf, A., H. Philip, A. Coutelle and J.F. Ritz. 1999. Découverte d'un chevauchement d'âge quaternaire au Sud de la grande Kabylie (Algérie), Geodynamica acta (Paris) 12 (2), 71-80.

Cakir, Z., M. Meghraoui, A.M. Akoglu, N. Jabour, S. Belabbesand L. Ait-Brahim. 2006. Surface deformation associated with the Mw 6.4, 24 February 2004 Al Hoceima, Morocco, earthquake deduced from InSAR; implications for the active tectonics along North Africa, Bull. Seism. Soc. Am., 96, 59-68.

Calvert, A., E. Sandvol., D. Seber., M. Barazangi., S. Roecker., T. Mourabit., F. Vidal., G. Alguacil., and N. Jabour. 2000. Geodynamic evolution of the lithosphere and upper mantle beneath the Alboran Region of the Western Mediterranean: constraints from travel time tomography. Journal of Geophysical Research 105, 1087110898.

Campbell, K. W. 1982. Bayesian analysis of extreme earthquake occurrences. Part I. Probabilistic hazard model, Bull. Seismol. Soc. Am. 72, 1689-1705.

Cherkaoui, T. E and A. El Hassani.2012. Seismicity and Seismic hazard in Morocco. Bulletin de l'Institut Scientifique, Rabat, section Sciences de la Terre, 2012, $n^{\circ} 34$, p. 45-55

Cornell, C.A. 1968.Engineering seismic risk analysis, Bull. Seismol. Soc. Am. 58, 1583-1606.

D'Acremont, E., M.A. Gutscher., A. Rabaute., B. Mercier de Lépinay., M. Lafosse, J.Poort., A. Ammar., A. Tahayt., P. Le Royc., J. Smit., D. Do Couto., R. Cancouët., C. Prunier., G. Ercilla., and C. Gorini. 2014. Highresolution imagery of active faulting offshore Al Hoceima, Northern Morocco. Tectonophysics, 632, 160-166.

Frizon de Lamotte, D., B. Saint Bezar and R. Bracène. 2000. The two main steps of the Atlas building and geodynamics of the western Mediterranean. Tectonics, vol. 19, $\mathrm{n}^{\circ} 4$

Gardner, J. and L. Knopoff. 1974. Is the sequence of earthquakes, in southern California, with aftershocks removed, Poissonian? Bull. Seismol. Soc. Am. 64, 1363-1367.

Goebel, T.H.W., D. Schoerlemmer., G. Dresen., and T.W. Becker. 2012. Stress-driven in $b$-values during stickslip on laboratoty fracture granite surfaces. Journal of Geophysical Research. Doi:10.1029

Gomez, F., Beauchamp, W., and M. Barazangi. 2000. Role of the Atlas mountains (northwest Africa) within the African-Eurasian plate boundary zone, Geology 28, 775-778.

Grassberger, P., and I. Procaccia. 1983. Measuring the strangeness of strange attractors. Physica D 9, 189-208

Gutenberg, B., and C. F. Richter. 1954. Seismicity of the Earth, Second ed., Princeton University Press, Princeton, New Jersey, 310 pp.

Hall, P. 1982. On estimating the endpoint of a distribution, Ann. Stat., 10, 556-568. 
Hamdache, M., J. A. Pelaéz, and K. Yelles Chaouche. 2004. The Algiers, Algeria earthquake (Mw 6.8) of the 21 May 2003: Preliminary report. Seism. Res. Letters, n3. May/June 2004., 75

Hamdache, M., Peláez, J.A., Talbi, A., and C. López Casado. 2010. A unified catalog of main earthquakes for Northern Algeria from A.D. 856 to 2008. Seismological Research Letters 81, 732-739.

Hamdache, M., J.A. Peláez, and J.M. Martínez Solares. 2012. Correlating Spanish IGN and Algerian CRAAG magnitudes for Northern Algerian earthquakes. International workshop, UNESCO - RELEMR. 13-16 February 2012. University of Malta. Sliema. Malta.

Hirata, T. 1989. Fractal dimension of fault system in Japan: fractal structure in rock fracture geometry at various scales. Pure Appl. Geophys 131(1/2):157-170.

Holschneider, M., G. Zoller, and S. Hainzl. 2011. Estimation of the Maximim Possible Magnitude in the framework of a Doubly Truncated Gutenberg-Richter Model. Bulletin of the Seism. Soc. Am., 101, 4, 16491659.

Kijko, A. and M.A. Sellevoll. 1989. Estimation of earthquake hazard parameters from incomplete data files, Part I, Utilization of extreme and complete catalogues. Bull. Seism. Soc. Am. 79, 645-654

Kijko, A. and M. A. Sellevoll. 1992. Estimation of earthquake hazard parameters from incomplete data files, Part II, Incorporation of magnitude heterogeneity, Bull. Seism. Soc. Am. 82, 120-134.

Kijko, A., and G. Graham. 1998. Parametric-historic procedure for probabilistic seismic hazard analysis. Part I: Estimation of maximum regional magnitude $m_{\max }$. Pure Appl. Geophys. 152, 3, 413-442.

Kijko, A. 2004. Estimation of the maximum earthquake magnitude, $m_{\max }$. Pure Appl. Geophys. 161, 8, 16551681.

Kijko, A and M. Singh. 2011. Statistical Tools for Maximum Possible Earthquake Magnitude Estimation. Acta Geophysica. Vol. 59, 4, 674-700.

Kijko, A and A. Smit. 2012. Extension of the Aki-Utsu b-value Estimator for incomplete Catalogs. Bull. Seism. Soc. Am. 102, 3, 1283-1287.

Kramer, S.L. 1996. Geotechnical Earthquake Engineering, Prentice Hall, New Jersey.

Lafosse, M., E. D’Acremont., A. Rabaute., B. Mercier de Lepinay., A. Tahayt., A. Ammar and C. Gorini. 2016. Evidence of Quaternary transtensional tectonics in the Nekor basin (NE Morocco). Basin Research.

Lonergan, L., and N. White. 1997. Origin of the Betic-Rif mountain belt. Tectonics 16, 504-522

López Casado, C., C. Sanz de Galdeano., S. Molina., and J. Henares. 2001. The structure of the Alboran Sea: an interpretation from seismological and geological data. Tectonophysics 338, 79-95.

Marquez-Ramirez, V. H., F. A. Nava and F. R. Zuniga. 2015. Correcting the Gutenberg-Richter b-value for effects of rounding and noise. Earthq. Sci. DOI 10.1007/s11589-015-0116-1

Marzocchi, W and L. Sandri. 2003. A review and new insights on the estimation of the b value and its uncertainty. Ann. Geophys. 46, 1271-1282.

McGuire, R.K. 1976. FORTRAN computer program for seismic risk analysis, Open File Report, 76-67, USGS, Menlo Park. 
Meghraoui, M., A. Cisternas and H. Philip. 1986. Seismotectonics of the lower Chéliff basin: structural background of the El Asnam (Algeria) earthquake, Tectonics, 5 (6), 809-836.

Meghraoui, M. 1988. Géologie des zones sismiques du Nord de l'Algérie. Paléosismologie, tectonique active et synthèse sismotectonique, Ph.D. thesis (Universite’' de Paris-Sud, 1988).

Meghraoui, M and S. Pondrelli. 2012. Active faulting and transpression tectonics along the plate boundary in North Africa. Annals of Geophysics, 55, 5, 2012. Doi: 10.4401/ag-4970

Mogi, K. 1962. Study of elastic shocks caused by the fracture of heterogeneous materials and its relation to the earthquake phenomena, Bull., Earthquake Res., Inst.,Univ., Tokyo, 40, 125-173.

Molchan, G. M., V.L. Keilis-Borok and V. Vilkovich. 1970. Seismicity and principal seismic effects, Geophys., J. 21, 323-335.

Mueller, C.S. 2010. The influence of maximum magnitude on seismic-hazard estimates in the central and eastern United States, Bull. Seism. Soc. Am. 100, 2, 699-711.

Negredo, A. M., P. Bird., C. Sanz de Galdeano and E. Buforn. 2002. Neotectonic modelling of the IberoMaghrebian region. Journal of Geophysical Research, vol. 107, no B11, 2292, doi: 10.1029/2001JB000743.

Nerenberg, M.A.H and C. Essex. 1990. Correlation dimension and systematic geometric effects, Phys. Rev. A. 42, pp 7065-7074

Nocquet, J.M., and E. Calais. 2004. Geodetic measurements of crustal deformation in the western Mediterranean and Europe, Pure Appl. Geophys., 161, 661-681; doi 10.1007/

s00024-003-2468-z.

Okubo, P.G. 1994. Seismicity associated with the continuing eruption at Kilauea Volcano, Hawaii [abs.]: Seismological Research Letters, v. 65, no. 1, p. 55.

Öncel, A.O., I. Main., Ö. Alptekin., and P. Cowie. 1996. Temporal variations in the fractal properties of seismicity in the north Anatolian fault zone between $31^{\circ} \mathrm{E}$ and $41^{\circ} \mathrm{E}$. Pure Applied Geophysics $147,147-159$.

Öztürk, S. 2012. Statistical correlation between b-value and fractal dimension regarding Turkish epicentre distribution. Earth Sci. Res. SJ. Vol. 16, No. 2 (December, 2012): 103 - 108

Öncel, A.O., Wilson, T. 2002. Space-time correlations of seismotectonic parameters and examples from Japan and Turkey preceding the Izmit earthquake. Bulletin Seismological Society of America 92, 339-350.

Pailoplee, S., and M. Choowong. 2014. Earthquake frequency-magnitude distribution and fractal dimension in mainland Southeast Asia. Earth, Planets and Space, 66, 8.

Peláez, J.A., Chourak, M., Tadili, B.A., Brahim, L.A., Hamdache, M., López Casado, C., and Martínez Solares, J.M. 2007. A catalog of main Moroccan earthquakes from 1045 to 2005. Seismological Research Letters 78, 614-621.

Peláez, J.A., M. Hamdache and Sanz De Galdeano. 2012. A spatially smoothed seismicity forecasting model for $M w \geq 5.0$ earthquakes in northern Algeria and Morocco.15 World Conf. Earth. Eng. 24 - 28 September 2012 , Lisboa, Portugal.

Peláez, J.A., M. Hamdache., C. Sanz de Galdeano., R. Sawires., and M. T.García Hernández. 2016. Forecasting moderate earthquakes in northern Algeria and Morocco. In: D’Amico, S., Ed., Earthquakes and Their Impact on Society, Springer, Berlin, ISBN 978-3-319-21752-9. 
Philip, H., and M. Meghraoui. 1983. Structural analysis and interpretation of the surface deformation of the El Asnam earthquake of October 10, 1980, Tectonics 2, 17- 49.

Pisarenko, V.F. 1991. Statistical evaluation of Maximum Possible Magnitude. Earth Physics 27, 757-763.

Pisarenko, V.F., Lyubushin, A.A., Lysenko, V.B., Golubieva, T.V. 1996. Statistical estimation of seismic hazard parameters: Maximum Possible Magnitude and related parameters. Bull. Seism. Soc. Am. 86, 691-700.

Rosenblueth, E. 1986. Use of statistical data in assessing local seismicity. Earthq. Eng. Struct. Dynam. 14, 325337.

Rosenblueth, E. and M. Ordaz. 1987. Use of seismic data from similar regions. Earthq. Eng. Struct. Dyn. 15, 619-634.

Sandri, L, and W. Marzocchi. 2007. A technical note on the bias in the estimation of the $b$-value and its uncertainty through the least squares technique. Annals of Geophysics, 50, 329-339

Scholz, C. H. 1968. The frequency-magnitude relation of microfracturing in rock and its relation to earthquakes. Bull Seismol Soc Am 58:399-415.

Scholz, C. H. 2015. On the stress dependence of the earthquake b value. Geophys. Res. Lett., 42, 1399-1402, doi:10.1002/2014GL062863

Schorlemmer, D., S.Wiemer, and M.Wyss. 2005. Variations in earthquake size distribution across different stress regimes, Nature 437, 539-542.

Schorlemmer, D., and J. Woessner. 2008. Probability of Detecting an Earthquake. Bull. Seism. Soc. Am., 98: 2103-2117

Serpelloni, E., G. Vannucci, S. Pondrelli, A. Argnani, G. Casula and M. Anzidei. 2007. Geophys. Journal Inter. 169, 1180-1200.

Spada, M., S. Wiemer., and E. Kissling. 2011. Quantifying a potential bias in probabilistic seismic hazard assessment: Seismotectonic zonation with fractal properties. Bull. Seism. Soc. Am. vol. 101, n 6 pp 2694-2711.

Stepp, J. C. 1972. Analysis of Completeness of the Earthquake Sample in the Puget Sound Area and Its Effect on Statistical Estimates of Earthquake Hazard. In Proceedings of the International Conference on Microzonation, Seattle, U.S.A., 2, pp. 897-910.

Stich, D., F. Mancilla, D. Baumont and J. Morales. 2005. Source analysis of the Mw 6.32004 Al Hoceima earthquake (Morocco) using regional apparent source time functions, J. Geophys. Res., 110, B06306; doi:10.1029/2004 JB003366.

Tate, R.F. 1959. Unbiased estimation: Functions of location and scale parameters, Ann. Math. Stat. 30, 341-366.

Turcotte, D. 1997. Fractals and chaos in Geology and Geophysics, Cambridge University Press, New York, 416 pp.

Udias, A., and E. Buforn. 1991. Regional stresses on the Eurasia Africa plate boundary derived from focal mechanisms of large earthquakes, Pure and Applied Geophysics. 136, 433-448.

Utsu, T. 1965. A method for determining the value of $\mathrm{b}$ in the formula $\log n=a-b m$ showing the magnitude-frequency relation for earthquakes, Geophys. Bull. Hokkaido Univ. 13, 99-103 
Weatherill, G., and P.W. Burton. 2009. Delineation of shallow seismic source zones using K-means cluster analysis, with application to the Aegean region. Geophys. J. Int., 176, 565-588.

Weichert, D. H. 1980. Estimation of the earthquake recurrence parameters for unequal observation periods for different magnitudes. Bull. Seism. Soc. Am. 70, 1337-1346.

Wells, D. L and K. J. Coppersmith. 1994. New empirical relationships among magnitude, rupture length, rupture width, rupture area and surface displacement, Bull. Seism. Soc. Am. 84, 4, 974-1002.

Wheeler, R. L. 2009. Methods of $m_{\max }$, estimation east of the Rocky Mountains, U.S. Geological Survey OpenFile Report 2009-1018, 44 pp

Wiemer, S, and K. Katsumata. 1999. Spatial variability of seismicity parameters in aftershock zones. J. Geophys. Res. 104 (B6), 13, 135-151.

Wiemer, S., and M. Wyss. 2000. Minimum Magnitude of Completeness in Earthquake Catalogs: Examples from Alaska, the Western United States, and Japan. Bull. Seism. Soc. Am., 90: 859-869

Wiemer, S. 2001. A software package to analyse seismicity: ZMAP, Seis. Res. Lett. 72 (2), 373-382

Wyss, M., F. Klein., K. Nagamine and S. Wiemer. 2001. Anomalously high b-values in the South Flank of Kilauea volcano, Hawaii: evidence for the distribution of magma below Kilauea's East rift zone Journal of Volcanology and Geothermal Research 106, 23-37 